\title{
Narrating self and topicality in AY and Elenu's stand-up comedy
}

\author{
Azeez Akinwumi Sesan \\ Skyline University, Nigeria \\ azeezakinwumisesan@gmail.com
}

\begin{abstract}
The narrative pattern and discursive strategies of stand-up comedy in Nigeria reveal some tropes and motifs that are contemporary to the socio-political realities of the country. These narrative/discursive strategies demonstrate three discourse types: salutation/greeting discourse, reporting discourse, and informing discourse. With these discourse types, stand-up comedians use themselves as the victims of the jokes in order to evoke laughter in the audience. The performances of stand-up comedy, however, have not been accorded due recognition of the functional arts that can be used to critique the failure of the ruling elite in the Nigerian State. This is because stand-up comedy is class-selective and occasion-driven. To evoke laughter in the audience and to comment on the reality of existence, stand-up comedians deploy language aesthetics, kinesics, and atmosphere. The modal transition from pure oral stage to the technological phase of performance informs the conceptualisation of media mediated performance (MMP) through recorded VCDs/DVDs and social media. Data on the stand-up comedy of $A Y$ and Elenu are collected through media mediated performances (MMP) on VCD. Data on the subject matter, topicality, and discursive strategies of AY and Elenu's (who are among ace stand-up comedians in Nigeria) jokes are analysed and discussed. With the subject matter and topicality of the jokes, this paper suggests that stand-up comedy performs the utilitarian functions of literary and performing arts. It entertains, moralises, satirises, and educates members of heterogeneous audiences on some values and ethos of the contemporary Nigerian society.
\end{abstract}

Keywords: stand-up comedy, AY show, solo performance, media mediated performance, oral performance.

\section{Introduction}

The art and science of stand-up comedy reveals its very nature as a blend of talent and training (Greenbaum 1999; Roberts 2000; Double 2014). This argument is premised on Thomas Hardy's description of poetry as emotion put into measure (Maynard 1991). For clarification, Hardy goes further by suggesting that emotion is natural and acquired with latent ability, while measure is learnt through training or education. This said, it is the position here to return to the 
age-long argument about the very nature of artistic and literary creativity with the quality of literary artists. This age-long debate refers to the issue of training and ability of artists. In this debate, there are two schools of thought. The first school is of the view that artists are born. The proponents and adherents of this school focus their argument on the talent of an artist: an individual with innate ability for literary and artistic creativity can excel in a chosen genre without any recourse to training. The second school is of the opinion that artists are made. The proponents and adherents of this school are of the view that artists can excel in a given genre if they are exposed to proper and adequate training. Considering the nature of artistic and literary creativity, the position here is that artists are born and made. There is a blend of talent and skills acquired through direct or indirect training in artistic and literary creativity.

The centrality of talent and training in the performance of stand-up comedy in contemporary Nigeria cannot be ignored. There are so many stand-up comedians in the country that it is difficult to count them. This indicates that the entertainment and creative industries in the country have taken further steps to enlarge the scope of creativity and innovation among willing upstarts that want to attain stardom and earn a living by making other people laugh. In Nigerian creative and entertainment industry, 'making people laugh' is not novel but there is novelty in its popularisation.

The social and psychodynamics of art in the pre-modern Nigerian societies revealed that artists were in the service of the community to correct its ills and vices. They carry out their responsibilities through language and performance aesthetics of the texts. The artists, in this regard, manipulate the text and context of their performance to ensure that the content and subject matter of the texts were properly registered in the consciousness of the audience. The artists have no limits with regard to the subject matter and thematic thrust of their texts. They, therefore, make reference to every individual and sector of the society as the butt of their jokes without any fear of intimidation or harassment in the course of and after the performance. Simply put, artists are at liberty and cannot be crucified for whatever happens on the performance floor.

The discourse of the oral performance of artists covers some important issues of performance aesthetics and theories such as improvisation, kinesics, proxemics, and chronemics that contribute to the overall effect of the performance. The proper appropriation of all these performance aesthetics assists the performer to attract, retain, and sustain the attention of the audience. The performers make serious efforts to ensure that their audience understand the subject matter and meaning of the texts of their jokes. Performers are able to record success in the course of their performance owing to the fact that they share the same socio-cultural and political backgrounds with the audience. Simply put, the audience demonstrates sound knowledge of the background of the jokes or humorous comments offered by the performers. These humorous comments only evoke laughter in the audience because they understand the incongruity in the given situation and the situations presented via humour. The use of incongruity in the context of this paper relates to the idea of irony. In most of stand-up comedies, artists make use of irony and sarcasm which thrive more on incongruity (the gap between reality and expression).

The synchronic and diachronic studies of comedy and comic genres in the pre-modern Nigerian societies revealed that performance texts played a significant role in social ordering and engineering (Ogunleye 2012; Ogundeji 2014). This is because the nature and ideology of the text address societal tensions and stress which can upturn the decorum and sanity of the society. To this end, comedians and comic performers queried the abnormalities and misdemeanours of individuals and groups in the society.

In the $60 \mathrm{~s}$ through $70 \mathrm{~s}$ and mid-80s, there were performances of comic sketches on stage, television, and films by artists such as Baba Sala, Lukuluku, Samania, and Chief Zebrudaya. This period ushered in a period of quasi-formal performance of stand-up comedy 
as a new brand. Some practitioners and performers of comedy and comic sketches have become popular or notorious for their comic performances through their routines and idiosyncrasies in speech behaviour, make-up, costume, and overall performance aesthetics. Such a performance, as it was, is not a new genre and not in any way related to the genre of stand-up comedy. It is rather a genre of drama that encourages the evocation of laughter through funny speeches and performances. The audiences of these comic performances never had a dull moment in the course of the whole show. The main attribute of these comic plays is that they are usually dialogic unlike stand-up comic shows that are usually solo performances.

Before the current boom in the business of stand-up comedy, there were occasional performances of stand-up comedy during some functions such as marriage, funeral, launching, and birthday. The master of ceremonies $(\mathrm{Em} \mathrm{Cee})$ at these functions used to make some funny jokes to make the events lively. Those who were not good at making jokes enlisted the services of individuals that could make funny jokes for the entertainment of the audience. At this stage, the comedians operated at a level of an informal economy. This is because the performance was not properly structured. The performer only spent a few minutes to reel out his/her jokes. In some situations, the performance of jokes at some of these functions was awkward and clumsy. This stage of stand-up comedy performance is informal and uncoordinated.

At the quasi-formal stage of stand-up comedy, there were usually impromptu performances because the comedian or 'stand-up' was an ad hoc performer who was given just a few minutes to perform. Some of the performers were not always included in the programme. This development did not encourage the performers to sharpen their skills and oratorical power. This situation persisted until around late $80 \mathrm{~s}$ when there was an injection of professionalism into the business of jokes in comedy clubs, events centre, and other organised and formal settings.

The turning point in the nature and form of stand-up comedy was in the late $80 \mathrm{~s}$, when Ali Baba emerged with some creativity and innovation. At this time, Ali Baba realized that making people laugh can be lucrative and professional. His endorsement as an ambassador of Guinness in the mid 1990s changed the fortune and art of Ali Baba as an ace comedian. In 1998, Ali Baba registered his company, Ali Baba Hiccupurathird. He went further by erecting three billboards in strategic positions in Lagos. These billboards carry the simple message "Ali Baba: Being Funny is serious Business". This period marked a turning point in the art and business of stand-up comedy in Nigeria. Since the time that Ali Baba had intervened to make the 'laughing business' a lucrative profession, other stand-up comedians, such as I Go Dye and Gbenga Adeyinka, have also made a contribution towards the advancement of stand-up comedy as a lucrative profession (Onogu 2014).

With the understanding of the history and nature of stand-up comedy in Nigeria, it is necessary to examine its meaning for the proper examination of its semantics. Stand-up comedy is an art form that is concerned with making people laugh at the instance of a joke 'cracked' by the stand-up comedian (Onogu 2014: 46). The basic feature of stand-up comedy is that it is a solo performance with an individual performer deploying oratorical skills and rhetorical tropes to make the members of the audience laugh at jokes made live on the stage.

\section{Stand-up Comedy and its Modal Transition}

The thesis of this section is that artistic/literary performance is not static but dynamic in its modality. This is consistent with the formalist ideal of form and content. In this line of thought, both form and content have a correlating effect on each other. This is similar to the ideal of story and plot in the notional discourse of the nature of text. Critics, over ages and climes, 
have therefore argued that the conception of literary and artistic performances have transcended their basic, pure, and 'crude' oral stage (Olorunyomi 2008; Layiwola 2010). This paper adopts the purity and crudity of oral text because the textual transaction takes place between the performer and its audience in oral-aural format and through the manipulation of the context of performance. Besides, the performance/text is transient without any possibility of revisiting. Across the cultures of the world, orality is considered as the basic quality of literature/performance. The core of this argument is that artistic/literary performance is primarily oral before its transition to other modes such as writing and its digital interface (internet, blogs, electronic media, etc.).

The modal transition of text from the oral stage to its digital interface is systemic, gradual, and conditional. Any forms of literary expression, therefore, cannot be properly tranformed without due consideration for the oral stage. There is transition from one mode of artistic/literary expression to the other based on the needs of humans to "arrest" time and manipulate the space of performance for their convenience. Primary issues in this transition are access, the negotiation of meaning, textual mutation, and the availability of performance accessories or aid to performance. More critical for creative production is the fact that the space of place is gradually yielding, in the general tradition of digital culture, to the space of flows, with implications for the different phases of textual identities (Olorunyomi 2008:198).

It is suggested that the modal transition from the oral stage through the written one to the technological phase is not based on displacement but on symbiosis. This is because "the electronic stage can only enhance, not displace, our appreciation of oral aesthetics in spite of the making of McLuhan's 'typographic man'" (Izevbaye 2014: 63). The underlined issue in the textual modality is the change in taste and fashion of the audience. One mode of textual experience in terms of production and consumption does not negate the other. There are, however, inter-generic and cross-generic references in the utilities of the texts. With these inter-generic and cross-generic references, texts in all their modes are mutable - a quality that prioritises text-based and reader-based theories of performance aesthetics. The success of any performance depends on the reaction of the audience to the quality of the medium and the texts. The turning point from the oral aesthetics of the texts began with the introduction of writing; the idea that Ong (2002) has termed the secondary stage of orality. Ong's position that writing is secondary to its oral mode is notional considering textual production and experience (Osundare 1981; Akinyemi 2011; Sesan 2014).

The performance of stand-up comedy has greatly benefited from the modal transition from oral phase to technological phase. The idea here is that stand-up comedy has enjoyed a modal transition from the stage of primary orality to the stage of "tertiary orality" (if such term exists and is permitted in the context of this paper). This idea does not foreclose the understanding that there are some traces of writing in the production process of stand-up comedy. Even if stand-up comedians do not hold papers on stage in the course of performance, the significance of writing in the pre-production stage cannot be overlooked. Jokes that are performed before the audience on the stage had once passed through the stage of writing particularly during the data collection and rehearsals of stand-up comedians (Greenbaum 1999; Roberts 2000). Writing cannot be rejected by stand-up comedians and other modern oral artists because of the frailties of memory. These frailties, caused at times by emotional and psychological disturbances, lead to memory failure and forgetfulness. In this situation, writing comes to rescue as a mnemonic tool (aid to memory). This is also because it offers opportunities of revision. Stand-up comedians are able to revise and rehearse their jokes repeatedly before the actual performance in the presence of the audiences of varying ideological and aesthetic orientations. With the significance of writing in the pre-performance stage of stand-up comedy, this paper opines that the text of the performance is "written-to-bespoken-as-if-not-written". 
The contemporary performance aesthetics has offered a new direction in the reading of texts in relation to the composition of the audiences, the physical space of performance and the temporal space of performance. This viewpoint returns us to our notion of "tertiary stage of orality" characterised by the multimedia performance of texts. In this regard, there are two classificatory paradigms of audience compositions: the primary audience and the secondary audience. The basic parameter adopted in the distinction between primary and secondary audiences of multimedia performance of texts and, in this context, the performance of stand-up comedy, is the immediacy of the physical space and temporal space. There is immediacy between the performer and the primary audience particularly in the course of series of live performances that are organised. The audiences that watch the performance live on stage are primary because they enjoy immediacy and promptness of reactions to the text and context of jokes that are performed on stage. The emergence and discourse of secondary audiences in the contemporary society are made possible with the technological innovations in textual production and consumption. With the technological innovation, discourses of performance aesthetics of oral texts now focus on the notion of media mediated performance (MMP). The notional conception of MMP suggests the possibility of a new reading of oral texts in a new mode. The freshness that is attached to live performances of oral texts and, in this situation, stand-up comedy is erased in the MMP with its secondary audiences. Media mediated performance (MMP) is the performance mode that enables (oral) texts to be stored in a format that makes replay, retrieval, pause, and other forms of editing possible. Simplifying the notion of media mediated performance (MMP), it is argued that it offers a fresh insight into textual modality with secondary audiences overcoming the limitations of the physical and temporal space. Thus, technology and its use play a significant role in MMP, the typology of the texts and the classification of the audiences. This is because "the new technology may create change in society, and [...] the direction of change is determined by the nature and function (use) of that technology in the adopting culture" (Schaniel 1988: 493).

Considering the function of the new technology, this paper opines that secondary audiences of stand-up comedy are remote and detached from the context of the live performance of the jokes. These audiences have access to the jokes through recorded versions of the performance on VCD, DVD, and social media such as YouTube. Secondary audiences have overcome the limitations of time and space with the ability to watch performances of stand-up comedy and their own convenience and pace. These secondary audiences always have the capacity to play back and determine how they want to watch the texts of stand-up comedies in retrieval modes of VCDs, YouTube, and DVDs. The contemporary reality is that there are different volumes and versions of media mediated performance (MMP) of stand-up comedy on VCDs and YouTube with different brand names such as A Night of Thousand Laughs and AY Live.

\section{Data and methodology}

Nigeria has produced a reasonable number of stand-up comedians. Some of these comedians are toasts of their respective audiences because of their creativity, durability, and topics of their jokes. Ayo Makun (AY) and Akinlami Babatunde Julius (Elenu) are in the category of stand-up comedians whose jokes are topical and durable. These comedians make use of topical issues such as politics and corruption to lampoon the system and the "culprits". These stand-up comedians see their jokes beyond the conception of art for art's sake. For this reason, their relevant jokes on topical issues are selected for analyses and discussion in this paper. Data are gathered from the recorded live performances in retrieval mode of VCDs. This affords the present writer the opportunity of replaying for checking the validity and reliability of facts in 
the analyses and discussion. The VCDs are watched several times to ensure that adequate and proper data are gathered. The data are analysed and discussed under the following subheadings: discursive strategies in stand-up comedy, topical themes, and motifs in stand-up comedy. This paper adopts a sociological approach in the analyses of data with some references to discourse types and discursive strategies used in stand-up comedy. The essence of the sociological approach is to assess the contribution of stand-up comedians and their art to national rebranding and re-orientation.

\section{Discursive strategies in stand-up comedy}

A stand-up comedian could be compared to an orator that manipulates language and context to communicate message and meaning. As an orator, stand-up comedians comply in their performance with rhetorical canons: invention, disposition, elucutio, memoria, and delivery. These five parts play a significant role in the attainment of communicative success. They form part of the oratorical order and forms for critical analysis and evaluation (Esuh 2006: 231).

In the course of his art and performance, a stand-up comedian probes the known and the familiar within context. The performance of a stand-up comedian and its discursive strategies require the comedian to attract, retain, and sustain the attention of an audience with different ideological and socio-economic backgrounds. It is in the light of this that the performer of stand-up comedy studies the audience composition and other performance aesthetics for effective communication and mutual intelligibility for all that are involved in the performance process. The audience and the performer share a similar need of entertainment but with varying responsibilities and mandates. The former has the mandate or responsibility to get entertained while the latter has the mandate to entertain. Thus, entertainment is central to the performance of stand-up comedy. In one of the stand-up comedy shows, Ali Baba tells the audience that he has the mandate to ensure that all the members of the audience are entertained with his jokes. In this direction, the ace comedian, during this show, asks about the ethno-cultural composition of the audience. Knowing this composition, he made jokes that cut across the major ethno-cultural groups of the audience. He was able to achieve his mandate through the manipulation of language and context of performance.

In the performance of stand-up comedy, there is close link between discourse type and activity type (Sarangi 2000: 22; Odebunmi 2010: 28; Filani 2015: 43). A stand-up comedian synchronises the discourse type with activity type in the course of the performance. In doing this, a stand-up comedian employs different forms of coding such as code switching and code mixing with the use of pidgin, English, and other forms of indigenous languages. Adetunji (2013: 6) identifies that three types of language are used in Nigerian stand-up comedy and these are the following: standard/Nigerian English, pidgin, and local languages. In his argument, Adetunji avers that Nigerian stand-up comedians make use of code switching to align themselves with the linguistic orientation of their audience for communicative efficiency. Adetunji's view is consistent with Michalik \& Sznicer's (2017) and Dore's (2018) that standup comedians connect with their audience through the communicability of their language. To them, a stand-up comedian is able to retain and sustain the interest of the audience through his/her language use. The selection of language and the synchronisation of discourse type and activity type in stand-up comedy enable the estrangement and defamiliarisation from the text (making the familiar unfamiliar with the literary and connotative use of language). Besides, "it is in oral performance also that one can elicit a reliable audience-response theory, because there is dissolution of the spatial gulf between the work and the audience through live enactment" (Fashina 2000:104). In the context of the stand-up comedy, the spatial gulf helps in the understanding of the jokes owing to the nature and texture of language. The performer 
uses language with some figures of speech such as simile, personification, metonymy, irony, metaphor, and paradox, with figures of language such as allusion, symbolism, and imagery, to create meaning. Despite the estrangement and defamiliarisation of the text, the heterogeneous audiences (with the parameters of ethno-cultural diversities, gender, and socio-economic backgrounds) are usually willing and ready conspirators in the interpretation, analysis, and enjoyment of the jokes.

Returning to the synchronisation between discourse type and activity type, there is a need to consider the discourse texts and contexts in relation to their influence on the quality of jokes. The quality of jokes refers to the degree of encore that particular jokes received in the course of performance. The psycho-social context of the jokes (relaxed, amusing, and pleasant) also contributes to the success of the jokes. The audiences have the mind-set that they are going to be amused and entertained. Rutter (2000) and Lockyer \& Myers (2011) are of the view that stand-up comedians predetermine their audience relations for effectiveness of their jokes. This situation involves the type of jokes to be made to evoke laughter and the situational contexts of the jokes. For this reason, any member of the audience that constitutes the butt of the jokes does not pick offence. The reader-response theory of the jokes suggests that the audiences have homogenous responses to the jokes as evident in their spontaneous laughter and encore at given jokes.

Filani (2015: 42) observes three categories of discourse types of stand-up comedy: Salutation/greeting Discourse Type (SDT), Reporting Discourse Type (RDT), and Informing Discourse Type (IDT). These discourse types are causal and linear. The discourse types are linear because it takes a discerning audience to know when a stand-up comedian moves from the first discourse type to the second and the third. The Salutation/greeting discourse type constitutes the opening remarks of the performer introducing his person and mission at the show. Filani (2015: 42) describes the function of SDT in the performance of stand-up comedy as follows:

SDTs open and start routines of comedians. Functionally, they indicate comedian's communicative intention, secure audience attention, and sustain audience mood. They also establish for both comedians and audiences that mutual attention, mutual willingness, and mutual beliefs are essential for the success and progress of stand-up performance. It is characteristic of the comedians to focus on themselves or their audiences in any SDT. They could foreground their personality, style, or anything connected to them, and/or the presence of the audience.

Stand-up comedians open the stage and performance through specific and unique performance aesthetics that mark them out of other performers. The essence of SDTs, in some situations, is for a performer to outshine others through attraction, retention, and sustenance of audiences' attention. On an Easter performance, Elenu begins with SDT to state his mission and set the tone of the whole performance. At the opening of the performance, Elenu states:

Text 1: Happy Easter, we need to address certain issues very clearly. I am not here to kill myself before anybody. Comedy is now like a restaurant. Some people go home and laugh when you crack jokes. Some will laugh when they get home. If my joke does not make you laugh now, it will make you laugh when you get home.

Elenu's SDT reveals the nature of his performance and the expectations of the audience. The implied message in the SDT is that some of the jokes may not evoke spontaneous laughter. This is because some jokes evoke laughter with transcended signification and extended metaphor. The new context of the appreciation of jokes, perhaps, at home, motor parks, offices, markets, and other social gatherings may evoke laughter. This understanding informs the 
nature and content of Elenu's SDT. Even the SDT, as expected, evoked laughter in the audience. The laughter is prompted by the manner of presentation and not by the message.

Reporting Discourse Type is a narrative/discursive strategy adopted by a stand-up comedian to detach him/herself from the actions and events of the narration. In this instance, the performer creates a social and psychological distance from the characters in the jokes and the audience. RDTs reveal the creativity of the performer in relating the text of the jokes with appropriate context and style. Filani's (2015: 43) view on the creative significance of RDTs is illustrative:

Whenever RDTs are adopted, comedians display their creativity by narrating what occurred or could have occurred in a manner that serves the purpose of their interaction with the audience. In addition, as a meta-pragmatic strategy, comedians use it to present their perspectives on the actions of characters in their joke.

The argument here is that Filani's meta-pragmatic strategy in RDTs is used to exaggerate the actions and events beyond certain magnitude. It is the exaggeration of the actions that actually evokes laughter in the audience. The audiences, in some situations, are familiar with the texts of the jokes. The defamiliarisation of the text, however, is achieved with the appropriation of language that makes the jokes evoke laughter.

Stand-up comedians often utilise the context of discourse to create RDTs in their performances. In this line of thought, this paper identifies two forms of social distance that a performer adopts in the course of performance. These are immediate social distance and remote social distance. The immediate social distance is related to the performance distance in the sense that stand-up comedians make use of the situational context to provide RDTs. Doing this, comedians look for a character in the audience and weave stories around this person. These characters are usually celebrities or popular figures to make the jokes effective and hilarious. The remote social distance, on the other hand, involves the use of shared background knowledge or information between a stand-up comedian and the audience to make a joke. This shared knowledge or information is often on public personalities, the social and political realities of the country. There is the use of immediate discourse type in stand-up comedy performance in Asaba (the capital of Delta State in the South geo-political region of Nigeria) during the performance of AY Show (Ayo Makun is one of Nigeria's ace stand-up comedians who regularly organises stand-up comedy shows across the country). During this show, AY made a joke on the spur of the moment on RMD (Richard Mofe Damijo) on the latter's good looks and popularity with women. RMD is a Nollywood actor and former Commissioner for Culture and Tourism in Delta State. In the performance, AY says "RMD has threatened many women's marriage/RMD is so cute". This joke employs RDTs as its framing. Ordinarily in off-stage discourse, the utterance may not evoke laughter but the personality and context of jokes evoke laughter in the audience.

The Informing Discourse Type (IDT) occurs whenever stand-up comedians frame themselves as one of the participants in the joke. In some instances, they could frame themselves as the target of their narration (Filani 2015: 43). The IDT connects stand-up comedians with the events and contexts of performance. The performer uses direct speech and involvement in the events that unfold in the narration. It is a sort of self-inscription and immersion in the narration. The IDT is best explained with the autobiographical theory of narration and performance. This theory suggests that every individual inscribes him/herself consciously or unconsciously in the narration (cf. Renza 1980: 269; Sigvartsen 2013: 7). This theory subscribes to the popular opinion that texts are not made in a vacuum. Authors/performers make texts from personal or collective experience in a society. The argument on autobiographical theory of stand-up comedy performance draws some insight from Gilbert's (1997: 317) position on stand-up comedy as an identity and cultural construct: 
Performing autobiography is, in one sense, something we all do every day. When creating a staged, public autobiographical performance, however, we select bits and pieces of ourselves to share with an audience. In the genre of stand-up comedy, performers present a pastiche of observations and characters both real and imagined. At bottom, however, is the autobiographical self - a multifaceted, protean entity that encompasses both on stage and off stage personae. Stand-up comics simultaneously perform self and culture, offering an often acerbic social critique sanctioned as entertainment because it is articulated in a comedic context.

In this situation, the performer has a double role as the narrator and a character in the narration. In literary/performance studies, autobiography is self-inscription in the text. The writer narrates personal experiences in the text, particularly with the use of the pronoun $I$. What autobiography theory suggests is that not all I-narratives are qualified as autobiographies. The style of autobiography in narration is adopted to create an association between the author and the text. The primary goal is to establish authenticity of the narration. It is not easy to detach the author from the text but the audiences suspend all forms of disbelief in the course of narration/performance. Suspension of disbelief as one of the basic characteristics of autobiography theory of narration is suggested in Schnipper's (2010: 348) description of first person narration:

First person narrators can take different positions with regard to the narrated events: First, they can tell a story in which they are or have been the hero/heroine; second, they can tell a story in which mainly figure as observers; or third, they can tell a story which has been transmitted to them by somebody else in an oral or written form and which they are merely "presenting literally" on paper now.

Taking into account Schnipper's view, it is argued that there is a conflation of other discourse types in the utilisation of the Informing Discourse Type. In order to give some sense of immediacy and spontaneity to the performance of their jokes, stand-up comedians deploy rhetorical devices that simultaneously point to their involvement with and detachment from the plot of the jokes. This is why the audiences need to be cautious of the fact that performance of the jokes is all about fancy and illusion. The present writer is of the view that stand-up comedians, with the autobiographical theory and the use of the IDT, surreptitiously demonstrate the adoption of Bertolt Brecht's alienation effect (A-effect). The concept of Aeffect suggests that artists present larger than life performances before the audiences, while the latter are expected to suspend all forms of disbelief. This paper, therefore, aligns its view of Aeffect with Mujumdar's (2013: 3) position that "the story or incident should be written and enacted objectively and without involvement of any kind". To this end, the audiences are not expected to attach any emotion to the text of the performance.

Despite the fact that the IDT is consistent with autobiographical theory, it reveals the creativity of stand-up comedians that are able to manufacture jokes on the spur of the moment. This paper, therefore, argues that spontaneity and immediacy characterise the adoption of the IDT in the performance of stand-up comedy. The performance of AY in the Asaba show of his edition of $A Y$ Live is illustrative of this. After the salutation of the dignitaries (the governor and the speaker of the State House of Assembly, among others) with the Salutation/greeting Discourse Type (SDT), the ace comedian adopts the IDT to express his gratitude to His Excellency, in a humorous manner, for sponsoring the show.

Text 2: The day I got to Asaba, I played lawn tennis with His Excel. I dey allow him to play me. But I dey think inside me that this man no know me, if not for sponsorship. His aides tell me that AY small small it is His Excellency. His Excellency said AY I will deal with you. 
The above text reveals the use of immediacy and extemporaneity in the performance of stand-up comedy. The comedian has immersed himself in the performance for some artistic and creative effects. The audiences do not care to interrogate the authenticity or veracity of the plot of the jokes. The speech evokes laughter because of the personality of His Excellency and his lack of "mandate" to publicly debunk the claim.

The autobiographical style of narration, as a feature of the IDT, can be used for selfappraisal or self-denigration by stand-up comedians. These two brands of self-inscription with the use of the IDT are meant to maintain the "positive and negative face" (Gilbert 1997: 327) respectively. The goal of these brands, however, is to evoke laughter by providing incongruity between the known and the unknown, as well as between the real and the imagined. Filani (2015: 48) and Gilbert (1997: 327) comment on the performance text of self-appraisal and self-denigrating humour. They argue that self-appraisal humour is not commonly used by stand-up comedians while they often use self-denigrating humour in their jokes. The use of self-denigrating humour by stand-up comedians has some functions such as re-branding of the comedians' status, the acknowledgement of the non-permanence of situations and conditions in life, satirizing the dignitaries that serve as the butt of the jokes and situating jokes in the contemporary socio-political and economic realities with stand-up comedians as the villains or victims of circumstance. With the use of self-denigrating humour, stand-up comedians are able to comment on and attack the state and its manager(s) with impunity. In line of this argument, this paper subscribes to Gilbert's (1997: 327) view:

Self-deprecation is safe entertainment because it does not abuse or offend the audience - in fact, it appears to reaffirm hegemonic values. It, like all marginal humour, is effective social control because it accomplishes what professional fools have always accomplished - critique with impunity - impunity granted, of course, by the status quo (emphasis in the original).

The above quotation suggests that stand-up comedians use self-denigrating humour as a tool to satirise the movers and shakers of the society in their presence. These comedians hide under this brand of self-narration to avoid being punished for whatever jokes performed on stage. Self-denigrating humour are ironical in the sense that members of the audience that constitute the butts of the jokes laugh at their own follies and shortcomings.

\section{Topical themes and motifs in Nigerian stand-up comedy}

Topicality, in the context of this paper refers to the relevance of the themes of stand-up comedy to the contemporary socio-political and economic realities, while motif refers to the recurrence of similar themes in each of the episodes of stand-up comedy. This idea is prompted by the fact that the essence of artistic and literary performance is the reflection and refraction of realities. Stand-up comedians have stepped into this role of artists with the themes and motifs of their jokes. They align their artistic responsibilities with the nature of comic genre of dramatic enactment that laughs at the societal frailties condemning, commenting, and redressing the societal ills without attracting wrath of any individual or a group of individuals. Stand-up comedians, in their jokes, unrepentantly speak the truth in the presence of those that can effect positive change in the society. In the performance of their jokes, Nigerian stand-up comedians draw their ideas from current affairs of the country.

Stand-up comedians draw their materials from the current issues and affairs of the country and hence the topicality of their jokes. In the position of this paper, topical issues that stand-up comedians focus on cover the five important spheres of politics, economy, religion, ethics, and entertainment. Stand-up comedians treat these areas with tact and carefulness to evoke laughter and to effect some positive change in the audience and the society by extension. 
In the course of their performance, stand-up comedians comment on the past and contemporary political issues of the country. Among the issues that attract the attention of stand-up comedians are the electoral process, elections, political culture, and socialization, governance as well as leadership and followership questions. These areas have become the foci of public interest about which stand-up comedians evoke laughter and at the same time provide food for thought. Some of the jokes that are performed by Nigerian stand-up comedians on politics and governance are satire on the political culture of the country. One of the jokes of Elenu on the political culture of Nigerians suggests that electoral malpractice goes beyond rigging or the cancellation of election results. In a stand-up comedy on the electoral process in Nigeria, he exposes how voters exploit situations to be involved in one form of electoral irregularity or the other. The joke goes as follows:

Text 3: Nigeria election is always funny. In 2015 election, people dey on queue waiting to elect who dey rule them. Na so one man, deaf and dumb dey come. People dey pity am saying this man try o. They come give im chance to cast his vote. After he don cast his vote finish, the deaf and dumb ma say "una thank you o".

[Nigeria election is always funny. In 2015 election, people were on queue waiting to cast their votes. One deaf and dumb man also arrived to cast his vote. Everybody on queue had pity for him and gave him chance to cast his vote. After casting his vote, the deaf and dumb man said "everybody thank you".]

This joke evoked laughter in the audience through the use of language with the proper mapping of the text and the context of the performance, and at the same time exposed the irregularity that characterises Nigeria's political terrain. The underlying message of this joke is that Nigerians are cheats that are unrepentant in exploiting every situation to their advantage. The critical issue here is that electoral malpractice takes any form in the country. The character in the joke succeeds in his craft because of the compassion that most Nigerians have for the physically-challenged individuals.

In the Volume 27 of $A Y$ Live show, there is a comic display of the whole electoral process, particularly during the collation of election results, the counting of the votes and the eventual declaration of the winner in Nigeria's 2015 general election. Although the whole process and situation are comically presented, the performance is a review in order to address the shortfalls for better and credible elections in the country.

The Nigerian police have become the butt of jokes of stand-up comedians. This is not unconnected to the general belief that the force is corrupt with a high degree of impunity. It is general belief that Nigerian police is notorious for bribery and corruption as well as for aiding and abetting crimes in some quarters. It is in the light of the aforementioned points that standup comedians comment on some of corruption-related issues in the Nigerian police in their jokes. In the volume 21 of $A Y$ Live in London, Elenu makes some jokes on Nigerian police. He comments on the re-branding of the Nigerian police with the change of their uniforms from complete black to blue top and black trousers. This is not enough in Elenu's view. The joke goes thus:

Text 4: They are rebranding Nigerian police. They have changed the uniform to blue and black. If I dey authority, I go commot all pockets. So, if you give money to an officer, he will say my pocket don full.

[They are rebranding Nigerian police. They have changed the uniform to blue and black. If I am in the position of authority, I will remove all the pockets. So, if you give money to an officer, he will say my pocket is full.]

This joke reveals the state of corruption in the Nigeria police. Officers at road blocks and check points do collect money from motorists and others that ply the roads with one means of 
transportation or the other. Instead of doing proper checking of the vehicles and particulars of drivers, officers of the Nigerian police collect money. This joke is an exposition of high degree of negligence and corruption among the officers of the Nigeria police. The implied message of the joke is that officers of the Nigerian police do not need or require pockets on their cloths while on duty, particularly at road blocks or check points. This is because pockets help them to keep the "booties" of their corruption.

Nigerian stand-up comedians also focus their attention on inexperience and the lack of quality education among some officers of the Nigerian police. The recruitment process in the police force encourages people with lower qualifications such as a Senior School Certificate Examination (SSCE) to apply. With this, the performance of these officers on the job is questionable and doubtful. Some of these officers do not know the penal and criminal codes of the country. These officers are not civil and polite in the way they deal with people. In most cases, they intentionally disrupt the order of proceedings of cases or investigations. This situation in the Nigerian police force is part of issues discussed in one of Elenu's joke in $A Y$ Live in London, volume 21:

Text 5: Nigerian police no go tell you sir. A black man standing in the sun holding a black gun in a black uniform can shoot any time. Nigerian police can ask for anything. In fact, Nigerian police dey do road safety job. One day, I dey pass. One officer stop me for not using seat belt. I told him that you don't know that the law has been changed. The law stated that if you don't tight your seat belt. You should tight the one around your waist very well. The officer replied with surprise: "Ehn-ehn, dey don change am. DPO no tell me o".

[Nigerian police will not refer to you as sir. A black man standing in the sun holding a black gun in a black uniform can shoot any time. Nigerian police can ask for anything. In fact, Nigerian police do the road safety job. One day, I was passing by. One officer stopped me for not using seat belt. I told him that you don't know that the law has been changed. The law stated that if you don't tight your seat belt, you should tight the one around your waist very well. The officer replied with surprise: "Ehn-ehn, they have changed the law. The DPO did not tell me."]

This joke reveals the ignorance and illiteracy of some members of the Nigerian police. These officers quote wrong laws to victimise and oppress innocent Nigerians. They go to the extent of twisting laws to their own favour. In the contemporary reality, officers of Nigerian police combine duties of other forces such as officers of Federal Road Safety Corps (FRSC), Vehicle Inspection Officer (VIO) and Customs. They do this by asking for vehicle documents, the driver's license and other irrelevant documents. They also go further by asking for the use of a seat belt and other accessories of vehicular movement. These jokes are made on Nigerian polity, politics, and police based on the need to effect corrections. In some of these shows, very important persons (VIPs) as well as the movers and shakers of Nigerian society are in attendance. These VIPs, in some situations, become the butt of the jokes of the stand-up comedians. The only exception to this is when these VIPs are politicians because stand-up comedians do not want to engage in face-threatening acts with politicians. If there is a cause to use politicians as butts of their jokes, stand-up comedians do so mildly because they do not want to challenge the status quo.

\section{Conclusion}

This paper has considered the narrative/discursive strategies and themes of stand-up comedies by AY and Elenu. These comedians use their own stories/personal experiences in the performance of their jokes and these have some literary and comic effects on their performance. The modality of stand-up comedy is primarily oral before its transition to the media mediated performance (MMP) on VCD/DVD and YouTube. The MMP, thus, 
encourages audience categorisation to primary and secondary. The basic difference in this categorisation is the immediacy and promptness in the performance process between the performer and the audience. Stand-up comedians adopt different discursive/narrative strategies such as the Salutation/greeting Discursive Type, the Reporting Discourse Type and the Informing Discourse Type in the performance of their jokes. In adopting these discourse types, stand-up comedians inscribe themselves in the jokes. Despite the opportunities offered by the new media, a large number of the audiences of stand-up comedy still prefer to attend live shows. Their presence at live shows encourages social mix and connections which secondary audiences may not enjoy. Topical issues in the texts of stand-up comedy promote their sustained relevance to Nigeria's entertainment industry. This is because the overt tension and stress in the Nigerian society is humorously represented to evoke laughter. Besides, the creative and comic representation of the social tension and stress takes away the audiences from the boredom and monotony of real-life experiences.

\section{References}

Adetunji, A. (2013). 'The interactional context of humour in Nigerian stand-up comedy'. Pragmatics 23.1, pp. 1-22.

Akinyemi, A. (2011). 'African oral tradition then and now: A culture in transition'. CentrePoint Journal (Humanities Edition) 14.1, pp. 27-51.

Dore, M. (2018). 'Humor negotiation in intercultural stand-up comedy', in Tsakona, V. and Chovanec, J. (eds.), Dynamics of Interactional Humor: Creating and Negotiating Humor in Everyday Encounters, Amsterdam: John Benjamins Publishing Company, pp. 105-126.

Double, O. (2014). Getting the Joke: The Inner Workings of Stand-up Comedy. $2^{\text {nd }}$ edition, London: Bloomsbury.

Esuh, P. (2006). 'Introduction to rhetoric', in Wilson, D. (ed.), Fundamentals of Human Communication, Ibadan: Stirling-Horden Publishers, pp. 222-237.

Fashina, N. O. (2000). 'Lit-orature development, world peace and the challenges of literary theory/criticism'. Journal of the Nigeria English Studies Association 11.1, 101-113.

Filani, I. (2015). 'Discourse types in stand-up comedy performances: an example of Nigerian stand-up comedy'. European Journal of Humour Research, 3.1, pp. 41-60.

Gilbert, J. R. (1997). 'Performing marginality: Comedy, identity and cultural critique'. Text and Performance Quarterly 17, pp. 317-330.

Greenbaum, A. (1999). 'Stand-up comedy as rhetorical argument: an investigation of comic culture'. Humor: International Journal of Humor Research 12.1: pp. 33-46.

Izevbaye, D. (2014). 'Literature and technology: A Nigerian perspective'. The Savannah Review 3, pp. 47-72.

Layiwola, D. (2010). A Place Where Three Roads Meet: Literature, Culture and Society. Ibadan: Ibadan University Press.

Lockyer, S. and Myers, L. (2011). 'It's about expecting the unexpected: Live stand-up comedy from the audiences' perspective. Participations: Journal of Audience and Reception Studies, 8.2, pp. 165-188.

Maynard, K. K. (1991). Thomas Hardy's Tragic Poetry: The Lyrics and the Dynasts. Iowa City: University of Iowa Press.

Mujumdar, S. (2013). 'Bertolt Brecht's concept of 'epic-drama' and alienation theory and 'Tamasha art' in Marathi theatre: A comparative study. Lapis Lazuli: An International Literary Journal 3.1, pp. 1-13.

Odebunmi, A. (2010) 'Code selection at first meetings: A pragmatic analysis of doctor-Client conversations in Nigeria'. InLiSt, 48, pp. 1-41. 
Ogundeji, P. A. (2014). Yoruba Drama in Time Perspective. Ibadan: Ibadan University Press.

Ogunleye F. M. (2012). Thespians and Cineastes as Engineers of the Nigerian Soul. Ile-Ife: OAU Press.

Olorunyomi, S. (2008) 'Orality as text in mutation', in Raji-Oyelade, A. and Okunoye, O. (eds.), The Postcolonial Lamp, Ibadan: Bookcraft, pp. 190-204.

Ong, W. J. (2002). Orality and Literacy: The Technologizing of the Word. London and New York: Routledge.

Onogu, W. S. (2014) 'Quality assurance and stand-up comedy in Nigeria'. Nigerian Theatre Journal 13.1 , pp. 44-52.

Osundare, N. (1981). 'From oral to written: Aspects of socio-stylistic repercussions of transition. Journal of African and Comparative Literature, 1, pp. 1-13.

Renza, A. L. (1980). 'The veto of imagination: A theory of autobiography', in Olney, J. (ed.), Autobiography: Essays Theoretical and Critical, Princeton: Princeton University Press, pp. 268-95.

Roberts, R. E. (2000). 'Standup comedy and the prerogative of art'. The Massachusetts Review 41.2, pp. 151-160.

Rutter, J. (2000). 'The stand-up introduction sequence: Comparing comedy comperes. Journal of Pragmatics 32, pp. 463-483.

Sarangi, S. (2000). 'Activity types, discourse types and interactional activity: the case of genetic counselling', in Sarangi, S. and Coulthard M. (eds.), Discourse and Social Life, Harlow: Longman, pp. 1-27.

Schaniel, W.C. (1988). 'New technology and culture changes in traditional societies'. Journal of Economic Issues 2 (1), pp. 491-502.

Schipper, M. (2010). "'Who am I?" Facts and fiction in African first-person narrative', in Olaniyan, T. and Quayson, A. (eds.), African Literature: Anthology of Criticism and Theory. Oxford: Blackwell Publishing, pp. 345-352.

Sesan, A. A. (2014). 'Yoruba folktales, the new media and postmodernism'. Khazar Journal of Humanities and Social Sciences 17.2, pp. 74-87.

Sigvartsen, A. L. (2013). Consciousness and Autobiography: A Search for the Roots of Referentiality in Life Writing. M. A. Thesis. University of Oslo.

\section{Videography}

AY Live in London, Volume 21. (2014). Directed by Patrick O. Odjegba. Performance by Elenu, Akpororo, Yaw, Iyanya, 9ice. Producer Ayo Richard Makun.

AY Live, Complete Happiness, Volume 27. (2015). Directed by Patrick O. Odjegba. Performance by AY, Elenu, Seyi Law, Onyeka Onwenu. Producer Ayo Richard Makun.

AY Live in Asaba, Volume 28. (2015). Directed by Patrick O. Odjegba. Performance by AY, Elenu, Pencil, Seyi Law. Producer Ayo Richard Makun.

AY Live on Easter Sunday, Volume 30. (2016). Directed by Patrick O. Odjegba. Performance by Seyi Law, AY, Ajebo, Pencil, Odogwu, Davido. Producer Ayo Richard Makun. 